\title{
OCEANOGRAPHY AS A CAREER
}

\author{
By John H. Steele
}

I

WOULD GUESS THAT, for most of us, oceanography is both a vocation and a career. Usually, presentations at meetings discuss the science. I was asked to talk about oceanography as a career-as a job. This presentation will be partly personal reminiscence, and part speculation about future prospects.

It is 50 years since I got my first degree in pure mathematics, with the emphasis on pure. We were not encouraged to solve differential equations. The highlight of my time was the announcement of a simple-and elegant-proof of the prime number theorem, a result already proven but the previous proof had been considered aesthetically unsatisfactory.

Since this was England in 1947, I went straight from University to two years "national service" at the Royal Aircraft Establishment, Farnborough, a very defencerelated institution. There I learned something useful: numerical methods to calculate optimal trajectories for groundto-air missiles. Just as significant for my future, I also acquired a passion for sailing around the English Channel.

When I was released from this conscription, I had to make choices-government or university, military or peaceful research. All I had to rely on were my experiences in the very different worlds of the math department and of research and development at Farnborough.

Pure mathematics creates a wonderful, ideal world, but I got the impression that those who inhabit it may be divided into a few geniuses, and a large number of teachers. Whereas places like Farnborough could provide opportunities for a wide spectrum of abilities. I had a sense that any individual entering that kind of orga-

John H. Steele. Woods Hole Oceanographic Institution, Woods Hole, MA 02543, USA. e-mail: jsteele@whoi.edu nization could find his (or her) own level of competence and a role for his interests.

So, in the end, I went into marine research in a government laboratory in Scotland-partly because of this comparison, partly to return to my home country, and also, in large part, because of my desire to spend time messing about in boats. Over the next two decades, I more than satisfied the last, bouncing around the North Atlantic in small research ships.

I have enjoyed it. The community of marine scientists expanded not just in numbers but in variety. Especially, the narrow constraints on what was considered relevant research, whether fisheries or missiles, were relaxed. We felt relatively free to choose problems that interested $u s$ - and get them funded!

Woods Hole (WHOI) went through this pattern of growth and diversification. In the early 1950 s, over $90 \%$ of the funding was from the Navy for work on acoustics, explosives, and the like. When I first worked at WHOI in the late 1950s; my funding was from the Atomic Energy Commission, which supported much of the biology.

These expansive decades for science, from the 1950 s to the 1980 s, were a contrast with marine science in the first half of this century. Not merely in the scale of the effort but in the culture-the attitude toward research. Before WWII, research was mainly directed toward applied ends such as fisheries, or it was an adjunct to academic teaching. After WWII, the research universities, or in our case the research-based departments of oceanography, arose as a realization of the desire of communities of scientists, supported by government, to carry out what came to be known as "basic" research.

During these decades, especially the 1960 s and 1970 s, this pattern seemed stable and immutable, giving us a secure role in society. That sense of security is cer- tainly threatened, if not gone. We tend to date the demise of our compact with society to 1989 . the end of the cold war. But it is not clear that the continual growth of science could have continued unimpeded. It is rather like the problems that arise from the developments in health care. And, like health care, this may require fundamental changes in the structure, in the relations between those who provide the money and those who do the work.

We are seeing this begin to happen. As funding shrinks relative to demand, there is increasing competition for the research elite who can attract and retain support from the diminishing pool. Scarce institutional income is used to provide special facilities for these stars. Conversely, post-docs and technical staff are most severely affected by the increasing uncertainties of the market place. The sense of community is impaired.

So we look for other sources of support, specifically from industry, or more exactly, from those industries that we feel should benefit from our research. Thus it is ironic that as "academia" seeks more funds from industry, the research divisions of the largest companies that, two decades ago, boasted of their academic alliances, are now focusing more and more closely on short-term proprietary problems.

Does that mean we should return to the earlier status of our science? For the individual researcher, one alternative has always been to treat research as an adjunct to a full-time teaching job. This was the general practice before WWII, and this is becoming much easier and more popular now that oceanographers are not tied to particular institutes. The other alternative for the individual is to seek work in "industry." We should remember that, for industry, our major product is not our research but our graduates. We do ourselves and our graduates, as well 
Table 1

An idealized job description for the academic researcher

- Research topics are selected by the investigator - curiosity liven. If we cannot get the right people, we will not enter a new field of research.

- The appointment-promotion-tenure process is based solely on scientific merit. Most oceanographic institutions have large biology departments in spite of the difficulty in marketing their skills.

- The criterion for judging output from grants and contracts is that the researchers made their "best effort" to realize the stated objectives. This acknowledges that there will be failures and encourages innovation and experimentation.

- The results of the research are expected, and often required, to be published in refereed journals.

as society, a disservice if we do not prepare students for this latter alternative.

But these are not options for research institutes or the research-dominated universities. Can institutions develop their own applied-or directed, or strategiccomponents? What would this mean in practice? I see these problems as involving not merely the quantity of our funding but also the character of our culture. Let me try to explain (Table 1).

The first of these criteria is often taken, by itself, to define academic or basic research. Of course curiosity is significant, but I believe that the other criteria are at least as necessary to capture the character of our community-the customs and formalities that have developed over the last few decades.

These ideal precepts are not always followed exactly. Posts are advertised to meet perceived funding opportunities. Researchers can be fairly flexible in their curiosity. Yet I would suggest that, taken together, they define our culture.

As a contrast or an alternative, I have tried to set out the criteria that might apply in the research division of a commercial organization (Table 2).

Taken together, the criteria in Table 2 define a different culture. I would make the same point as before. Directed research is only one of the defining features, and not necessarily the most important. This culture is very successful in organizations like Stanford Research Institute and A. D. Little, as well as in the research and development divisions of large corporations. These are the organizations against which academic institutes would be competing if they wish to enter the arena of commercial or industrial research and development.

As an example, consider the developing requirements for environmental audits conducted by independent organizations, like financial audits. Such outside audits are being mandated in several European countries. They may be introduced here, voluntarily at first, then as a legal requirement. It could become big business. especially in the coastal domain. Where will the appropriate skills be taught? Where will the methodology--legal as well as environmental-be developed? What organizations will perform the audits? In particular, would there be a role for oceanographic institutes or departments? This is a hypothetical example, but it encompasses the need to reconsider organization as well as subject matter.

\section{What Are the Options?}

One possibility is that the traditional role of teaching could be replaced by directed projects so that each individual researcher has a share in both curiosity and contract research. I doubt this would work, in part because the best and the brightest will still be able to get full-time support to follow their noses. But mainly I believe it is because, as outlined above, the cultures are so different and the competition for directed contracts is just as severe.

There is a further option. We now have very large community projects such

Table 2

Factors defining directed research

- Contracts are written to meet externally defined objectives, to get results required for industrial innovations, by mission agencies or through edicts of Congress.

- Researchers are selected for their ability to adapt to these challenges, and to provide solutions within constraints of time and costs.

- Contracts will specify "deliverables" rather than "best effort." This can produce quite different assessments of fiscal risk to an organization.

- The proprietary value of the results can require that they remain unpublished. Litigation on environmental issues can result in "gag orders" on data collected by State and Federal agencies as well as by industry. as Global Change that have extended the networks of scientists well beyond the bounds of individual institutions. These scientific guilds are intended to work on issues that we, the science community, define as being of great social relevance. This is one way to preserve that spectrum of abilities and, especially, the sense of community. The question is: Can these large international projects provide us with new social contracts between science and society? The jury is still out, and it is not at all clear that this will be acceptable as a general solution, either to the individual researcher or to the public-or to Congress.

However, I see one lesson from the past decades. Solutions are not developed solely within research organizations but by creating new patterns among them. Witness the Office of Naval Research and the National Science Foundation after WWII, or, more recently, the networks of the "global" programs. or the new science directorates in the European Union that provide the driving force, as well as funds, for new programs in marine science in the countries of Europe.

Science in general and oceanography in particular are not as significant parts of the budget as is health care, but the costs and benefits catch the attention of those with power. Whether a reform occurs through command and control, or whether the market place triumphs here as in health care. the administrative solution may require a different style of management.

So, whatever the trends in funding, I would suggest that it will not be sufficient for the research institutes of the future merely to be smaller. more compact versions of their ancestors in the 1980s. New kinds of organizations, with different cultures, may need to emerge.

It would be foolhardy to try to predict the patterns in these cultures. It will certainly be challenging. not only to the administrators but for the researchers who, after all, are most adept at seeing new connections between disparate entities, and who are the entrepreneurs in our system.

I started on a personal note so let me end on one. I am often asked if I am glad that I was a working oceanographer in the expansive period of the 1960s and 1970s. The answer is: Yes, it was great fun then. Perhaps it is not so much fun now, but the science is even more exciting. And oceanography is well placed to adapt its culture to meet the new compacts with society. $\square$ 